\title{
Association of common WRAP 53 variant with ovarian cancer risk in the Polish population
}

\author{
Krzysztof Mędrek • Piotr Magnowski • Barttomiej Masojé • \\ Anita Chudecka-Głaz $\cdot$ Bogdan Torbe $\cdot$ Janusz Menkiszak • \\ Marek Spaczyński · Jacek Gronwald · Jan Lubiński · Bohdan Górski
}

Received: 17 July 2012/Accepted: 19 November 2012/Published online: 29 November 2012

(C) The Author(s) 2012. This article is published with open access at Springerlink.com

\begin{abstract}
Among many alterations within the TP53 gene the rs1042522 (C72G, p.Pro72Arg) has been associated with numerous cancers, however the results differ between populations for opposite Pro or Arg alleles. Similar thus inconclusive results are observed in ovarian cancer, which may suggest that the rs 1042522 does not influence ovarian carcinogensis directly, but might be linked to another pathogenic alteration. WRAP53 which overlaps the TP53 is required to maintain normal levels of p53 upon DNA damage, but also when altered may independently increase the risk of cancer. To evaluate the association between three SNPs located in WRAP53-TP53 region: rs1042522, rs2287497, rs2287498 and ovarian cancer risk in Polish population we genotyped 626 cases and 1,045 healthy controls. Our results provide the evidence for an association between studied SNPs and a risk of invasive ovarian cancer in Poland. We found that $\mathrm{CC}$ homozygotes in rs 1042522 were more frequent in cancers when compared to controls $(\mathrm{OR}=1.46, p=0.03)$. Similarly in WRAP53
\end{abstract}

\footnotetext{
K. Mędrek (凹) · B. Masojć · J. Gronwald · J. Lubiński ·

B. Górski

Department of Genetics and Pathology, Pomeranian Medical

University, Szczecin, Poland

e-mail: kris.medrek@gmail.com

K. Mędrek · A. Chudecka-Głaz · J. Menkiszak

Department of Gynecological Surgery and Gynecological

Oncology of Adults and Adolescents Pomeranian Medical

University, Szczecin, Poland

P. Magnowski · M. Spaczyński

Department of Gynecological Oncology, Karol Marcinkowski

University of Medical Sciences, Poznan, Poland

B. Torbe

West Pomeranian Center of Oncology, Szczecin, Poland
}

both TT homozygotes in $\mathrm{rs} 2287497 \quad(\mathrm{OR}=1.95$, $p=0.03)$ and AA homozygotes in rs $2287498(\mathrm{OR}=2.65$, $p=0,01)$ were more frequent among cases than healthy individuals. There is also a suggestive evidence that specific homozygosity of studied SNPs in TP53-WRAP53 region is significantly overrepresented in ovarian cancer patients. In conclusion SNPs in WRAP53 (rs2287497 and rs2287498) have stronger association with an ovarian cancer risk than rs1042522 in TP53.

Keywords WRAP53 - TP53 - Ovarian cancer · Genotyping $\cdot$ SNP $\cdot$ Polish population

\section{Introduction}

The TP53 is one of the most distinctive genes in carcinogenesis. Role of the $\mathrm{p} 53$ protein in regulation of cell cycle, cell growth and maintenance of genomic stability has been largely described. Numerous alterations in p53 lead to neoplasmatic transformation. A rare familial Li-Fraumeni Syndrome was associated with germline mutations in this gene. In families with Li-Fraumeni syndrome most commonly observed neoplasms are: soft tissue sarcomas, osteosarcomas, brain tumors, breast cancer, leukemias, and adrenocortical tumors, but not ovarian cancer [1] However, over 200 epidemiologic studies evaluated ovarian cancer risk associated with SNP variants in TP53. Among them the TP53 $215 \mathrm{G}>\mathrm{C}$ (rs1042522, p.Pro72Arg) is one of the most commonly disputed. The results differ between populations with little or no evidence for the risk of cancer for opposite Pro or Arg alleles [2-8]. Similar thus inconclusive results are observed in ovarian cancer [9-11] and thereby reproduce previous findings. These equivocal data may suggest that the TP53 rs1042522 does not influence 
carcinogensis directly, but might be linked to another pathogenic alteration responsible for higher risk of ovarian cancer. One of the candidate gene is the WRAP53 (also denoted as WDR79 and TCAB1) located on chromosome $17 \mathrm{p} 13$ which partly overlaps the TP53 and interacts with the $5^{\prime}$ UTR of p53. WRAP53 is required for control and induction of p53 upon DNA damage to maintain normal levels of p53 in the cell preventing its deprivation which may then lead to a cancer [12] The identification of Wrap53 as a regulator of p53 shows that dysfunction of Wrap53 itself may be a separate cause leading to a cancer $[13,14]$ Recent reports suggested that common variations in WRAP53 may independently increase risk of estrogen receptor negative breast cancers [15] and correlates with poor prognosis of head and neck cancer [16].

Aim of this study was the analysis of association between SNPs located in WRAP53-TP53 region: rs1042522, rs2287497, rs2287498 and ovarian cancer risk in the Polish population.

\section{Materials and methods}

The studied group consisted of 626 ovarian cancer patients from the registry of International Hereditary Cancer Centre in Szczecin, Poland, who were diagnosed in years 2003-2009 in cooperating Oncology Centers in Szczecin and Poznań. All cases were histologically or cytologically confirmed. The control population consisted of 1045 healthy women who visited their family doctors in the area of Szczecin. Mean age and age structure did not differ significantly between cases and controls (age range 26-79 vs $27-79$, mean age 55.5 vs 56 respectively).

The study protocol was approved by the Institutional Review Board of the Pomeranian Medical University, the approval was obtained from all cooperating institutions, and signed informed consent for genetic testing was obtained from all participants.

$10 \mathrm{ml}$ of peripheral blood samples for DNA extraction were acquired from cases and controls. The DNA extraction was performed in all individuals using the non-enzymatic method [17].

All samples were genotyped with use of Simple Probes on Roche LightCycler 480 in 384 well plates in $10 \mu \mathrm{L}$ PCR reaction using 1:10 dilution of LightCycler 480 Genotyping Master, $0.5 \mu \mathrm{M}$ of excess primer, $0.05 \mu \mathrm{M}$ of limiting primer, $0.6 \mu \mathrm{M}$ of probe and $\sim 20 \mathrm{ng}$ of DNA according to Roche Applied Sciences Genotyping Master Mix instructions.

All statistical calculations were performed using the common homozygous of each SNP as the reference value. Each of the SNPs was evaluated individually per genotype by calculating odds ratio (OR), $95 \%$ confidence interval $(95 \% \mathrm{CI}), p$ values using a chi ${ }^{2}$ test.
Genotype distributions of all three examined SNPs in control population were in accordance with Hardy-Weinberg equilibrium: rs1042522 $(\mathrm{MAF}=0.28, H W E=0.19)$; rs2287497 $(\mathrm{MAF}=0.12, \quad H W E=0.65), \quad$ rs 2287498 $(\mathrm{MAF}=0.10, H W E=0.57)$.

\section{Results and discussion}

The distribution of the genotypes among ovarian cancer samples revealed an association of studied SNPs with ovarian cancer risk. Rs1042522 CC homozygotes were more frequent in cases when compared to controls $(\mathrm{OR}=1.46)$ (Table 1). Similar association was observed for WRAP53 rs2287497 and rs2287498 where TT homozygotes and AA homozygotes, were more frequent among cases than controls $(\mathrm{OR}=1.95,2.65$, respectively) (Table 1). All the results were statistically significant.

A combined analysis of examined three SNPs showed an even stronger association with ovarian cancer risk for cases with three rare homozygotes $\mathrm{CC}+\mathrm{TT}+\mathrm{AA}$ versus wild type homozygotes $\mathrm{GG}+\mathrm{CC}+\mathrm{GG} \quad(\mathrm{OR}=4.76$ $p=0.0006$ CI $95 \%$ 1.84--12.32). These calculations were statistically significant and included Bonferroni correction. However, detailed studies around this region will be needed to clarify the observed association of that specific homozygosity in other populations.

The ambiguous associations found for rs1042522 with little or no evidence for the risk of ovarian cancer were previously described in different populations, similarly neither TP53 germline mutations nor Li-Fraumeni syndrome was proven to be associated with an increased risk of ovarian cancer. Hence the hypothesis that an evaluation of SNPs located in close proximity to TP53 may reveal that rs1042522 is just a marker of other pathogenic alleles. WRAP53 is one of the candidate flanking genes to TP53 located on antisense strand to TP53. An analysis of the literature revealed studies involving genotyping of 23 SNPs

Table 1 Distribution of genotypes among ovarian cancers

\begin{tabular}{|c|c|c|c|c|c|c|c|c|c|}
\hline \multirow[t]{2}{*}{ Site } & & \multicolumn{2}{|c|}{ Cases } & \multicolumn{2}{|c|}{ Controls } & \multirow[t]{2}{*}{ OR } & \multirow[t]{2}{*}{$p$} & \multicolumn{2}{|c|}{ CI $95 \%$} \\
\hline & & $n$ & $(\%)$ & $n$ & $(\%)$ & & & & \\
\hline \multirow[t]{3}{*}{ rs10425225 } & $\mathrm{CC}$ & 59 & 9.4 & 72 & 6.9 & 1.46 & 0.03 & 1.00 & 2.11 \\
\hline & CG & 265 & 42.3 & 436 & 41.7 & 1.08 & 0.25 & 0.88 & 1.33 \\
\hline & GG & 302 & 48.2 & 537 & 51.4 & 1.00 & 1.00 & & \\
\hline \multirow[t]{3}{*}{ rs2287497 } & TT & 20 & 3.2 & 17 & 1.6 & 1.95 & 0.03 & 1.01 & 3.76 \\
\hline & TG & 118 & 18.9 & 220 & 21.1 & 0.89 & 0.19 & 0.72 & 1.18 \\
\hline & $\mathrm{CC}$ & 488 & 78.0 & 808 & 77.3 & 1.00 & 1.00 & & \\
\hline \multirow[t]{3}{*}{ rs 2287498} & AA & 19 & 3.0 & 12 & 1.2 & 2.65 & 0.01 & 1.27 & 5.50 \\
\hline & GA & 99 & 15.8 & 184 & 17.6 & 0.90 & 0.24 & 0.69 & 1.18 \\
\hline & GG & 508 & 81.2 & 849 & 81.2 & 1.00 & 1.00 & & \\
\hline
\end{tabular}


in the TP53 region including some variants outside the TP53 coding sequence, among them SNPs located in fact within WRAP53. Previously published multicenter pooled data suggested an association between rs2287497 and rs2287498 with serous invasive ovarian cancers, but the results were inconsistent between analyzed populations $[10,11]$. rs 2287498 is a synonymous amino acid change in exon 2 (F150F) of WRAP53 gene, expected to affect function at a splice site, rs2287497 is an intronic change, however supportive of an association [11]. The study of Schildkraut included a small number of Polish ovarian cancer patients, however narrowed to serous ovarian cancer cases only, because of the a priori belief that TP53 variants might be more closely related to serous cancers [10]. Schildkraut findings showed a trend consistent with our results, but due to relatively smaller groups (118 ovarian cancers vs. 618 controls) the scores were not statistically significant leaving the case open.

Our results provide the evidence for an association between SNPs both in TP53 and WRAP53 and a risk of invasive ovarian cancer in Poland. Our results might be a suggestive evidence that specific homozygosity of several SNPs in TP53-WRAP53 region is significantly overrepresented in ovarian cancer patients. The observations suggest a stronger association of both rs2287497 and rs2287498 (WRAP53 variants) than of rs1042522 (TP53 variant) and lead to a conclusion that SNPs in WRAP53 is more strongly associated with an ovarian cancer risk than rs1042522 in TP53. It is possible that other variants of WRAP53, not selected for the evaluation, are also related to the disease.

Open Access This article is distributed under the terms of the Creative Commons Attribution License which permits any use, distribution, and reproduction in any medium, provided the original author(s) and the source are credited.

\section{References}

1. OMIM 2012. http://www.ncbi.nlm.nih.gov/omim/. [Online]

2. Noma M et al (2004) Association of p53 genetic polymorphism (Arg72Pro) with estrogen receptor positive breast cancer risk in Japanese women. Cancer Lett 210(2):197-203
3. Zhu ZZ et al (2007) Association of the TP53 codon 72 polymorphism with colorectal cancer in a Chinese population. Jpn J Clin Oncol 2007(37):385-390

4. Koushik A et al (2006) p53Arg72Pro polymorphism and risk of colorectal adenoma and cancer. Int J Cancer 2006(119): 1863-1868

5. Kalemi TG et al (2005) The association of p53 mutations and p53 codon 72, Her 2 codon 655 and MHTFR C677T polymorphism with breast cancer in Northern Greece. Cancer Lett 2005(222): $57-65$

6. Buyru T, Tigli H, Dalay N (2003) p53 codon 72 polymorphism in breast cancer. Oncol Rep 2003(10):711-724

7. Damin AP et al (2006) Evidence for an association of TP53 codon 72 polymorphism with breast cancer risk. Cancer Detect Prev 2006(30):523-529

8. Ohayon T et al (2005) The R72P p53 mutation is associated with familial breast cancer risk in Jewish women. $\mathrm{Br} \mathrm{J}$ Cancer 2005(92):1144-1148

9. Agorastos T et al (2004) P53 codon 72 polymorphism and correlation with ovarian and endometrial cancer in Greek women. Eur J Cancer Prev 13(4):277-280

10. Schildkraut J et al (2009) Single nucleotide polymorphisms in the TP53 region and susceptibility to invasive epithelial ovarian cancer. Cancer Res 69(6):2349-2357

11. Schildkraut JM et al (2010) Association between DNA damage response and repair genes and risk of invasive serous ovarian cancer. PLoS ONE 5(4):e10061

12. Mahmoudi S et al (2009) Wrap53, a natural p53 antisense transcript required for p53 induction upon DNA damage. Mol Cell 33(462-471):2009

13. Farnebo M (2009) Wrap53, a novel regulator of p53. Cell Cycle 8(15):2343-2346

14. Saldaña-Meyer R, Recillas-Targa F (2011) Transcriptional and epigenetic regulation of the p53 tumor suppressor gene. Epigenetics 6(9):1068-1077

15. Garcia-Closas $\mathrm{M}$ et al (2007) Common genetic variation in TP53 and its flanking genes, WDR79 and ATP1B2, and susceptibility to breast cancer. Int J Cancer 121(11):2532-2538

16. Mahmoudi $\mathrm{S}$ et al (2011) WRAP53 promotes cancer cell survival and is a potential target for cancer therapy. Cell Death Dis 2:e114

17. Lahiri DK, Schnabel B (1993) DNA isolation by rapid method from human blood samples:effects of $\mathrm{MgCl} 2$, EDTA, storage time, and temperature on DNA yield and quality. Biochem Genet 1993(31):321-328 